\title{
Jew or Jew? A Note on Orthography
}

Throughout this book I have chosen to italicize the noun Jew. Jew in italics may be read as signifying a word, figure, person, allegory, metaphor, phantasm, caricature, synecdoche, image, stereotype, identity, persona, and the like. To what may be the consternation of many readers, I do not employ italics (or "scare quotes"), as opposed to roman type, to distinguish between real Jews - or "real" Jews — and Jew(s) as figment or figure, nor between Jew as self and Jew as other. It serves the critical aims of this study to keep all dimensions of the word Jew in provocative and, I hope, productive tension with one another. The same aim conditions the occasional merging of the singular (Jew) and plural (Jews) through the use of the parenthetical $(s)$-as in Jew $(s)$. The word Jewish is rarely italicized here, however, as it seems often to carry a far more circumscribed charge than does the noun form. I address this distinction further, below.

In italicizing every occurrence of the term Jew (apart from those that appear in quotations by other authors), I invite the reader always to read the term with the complex depth and dimensionality it harbors, and to maintain the sense of heightened attentiveness to it that italics tend to evoke. To this end, as well, I often treat the collective form of the wordJews or the Jews - grammatically as a singular, rather than plural, noun. Again, this choice is intended to interrupt the equivalency reflexively assumed between word and material object/subject, and to replace that unselfconscious equivalency with the critical tensions and questions associated with the word as a cultural artifact. This is to say, even when the word Jews is used to designate a group of people who self-identify or are identified by others by the term, a far larger-or, at times, far more partial - world of meanings and questions inevitably attends such usage. To the best of my ability, I avoid treating the word as though it bore a single or self-evident definition. Rather, the word Jew $(s)$ and its worlds and ways of meaning are precisely the objects and subject matter of this study. 

JEW 
